\title{
Production Characteristics of the United States Pecan Industry
}

\author{
Bruce W. Wood \\ U.S. Department of Agriculture, Agricultural Research Service, Southeastern Fruit \& Tree-Nut Research \\ Laboratory, P.0. Box 87, Byron, GA 31008 \\ Additional index words. alternate beating, irregular bearing, biennial bearing, yield. marketing, Carya illinoinensis, Carya \\ illinoensis, periodicity, cycles, price

\begin{abstract}
The cyclic, alternate bearing and correlative aspects of U.S. produced pecan [Carya illinoinensis (Wangenh.) K. Koch] nuts are characterized. An attempt to forecast production using stepwise autoregressive techniques identified a national level biennial cycle for cultivar (CV) and seedling (SC) class nuts and a novemennial (9 year) cycle for SG class nuts. The intensity of the biennial cycle at the national level has generally been low to moderate over the last 50 years for $\mathrm{CV}$ and SG class nuts with no clear time trend being expressed. During the most recent years (1979-1991), national production of CV class nuts has not exhibited pronounced bienniality, whereas that of SG class nuts exhibited a moderate bienniality. The nature of the the irregularity of cycling of U.S. and state production appears to nullify the use of univariate polynomial equations as a practical tool for accurately forecasting nut production. Nut production within individual states was also cyclic, with 2-, 3-, 5, 6-, 10-, 12-, 14-, 15-, and 16-year cycles, depending on state and nut class. The most intense contemporary biennial cycles for CV class nuts were from Oklahoma, South Carolina, and North Carolina, whereas cycling of SG class nuts was most intense in Texas and Oklahoma. Correlations of production within and among states indicated that most interrelationships are relatively weak; however, national production of $\mathrm{CV}$ class nuts are highly correlated $(r=$ 0.96) with the production of CV class nuts in Georgia, whereas that of SG class nuts is most correlated with that of Louisiana.
\end{abstract}

The U.S. pecan industry has historically experienced difficulties forecasting in-shell nut production and expanding domestic and export markets (Epperson and Allison, 1980; Swink, 1991; Young, 1991; U.S. Dept. Agr., 1989). Forecasting-related problems are largely associated with the alternate bearing tendency of the crop; hence, both pricing and supply typically exhibit excessive variability (Young, 1991). The negative ramifications associated with both could be moderated if yield could be accurately forecasted (Young, 1991). Previous efforts to forecast production by Wright et al. (1990) for individual trees and by Gemoets et al. (1976) for national production have been frustrated by the innate tendency for individual pecan trees to produce crops in alternate years. Alternate bearing is exhibited by most polycarpic plants (Monselise and Goldschmidt, 1982), is especially pronounced in the genus Carya (Fowells, 1965), and can induce extreme fluctuations in the quantitative and qualitative aspects of nut yield. These alternations by individual trees can be expressed as cycles with quasi-regular periods (Wood, 1991). Two-year periods (biennial) are typical, although longer periods (triennial, quadrennial, and nearly irregular, etc.) also occur (Wood, 1991).

The alternate bearing behavior exhibited by individual trees exists as a statistical entity at the orchard level and may be similarly expressed at the state and national levels. This effect, therefore, influences marketing efforts and industry stability (Young, 1991). Despite the substantial negative economic impact of cycling irregularities on the pecan industry, little effort has been made to characterize the phenomenon at the state and national levels or to estimate its predictability. Gemoets et al. (1976) appear to have made the only such attempt. They used power spectral analysis to provide evidence for cycling (from 1919 to 1975) at the national (United States) level and concluded that production cycles were present for both CV (2.5 and 11-16 years) and SG ( 2 and 4 years)

Received for publication 9 Dec. 1991. Accepted for publication 2 Nov. 1992. I gratefully acknowledge the invaluable statistical assistance of William R. Joyner and Victor Chew. The cost of publishing this paper was defrayed in part by the payment of page charges. Under postal regulations, this paper therefore must be hereby marked advertisement solely to indicate this fact. class nuts, but did not ascertain the cycling patterns exhibited in individual states, characterize cycling intensity, or identify interstate or intrastate relationships. Since such factors influence pricing and marketing and, since the nature of the industry has substantially changed (Wood et al., 1990) subsequent to its initial characterization by Gemoets et al. (1976), the present analysis characterizes the production and cycling processes being expressed within the huge-scale production units of the U.S. pecan industry and assesses the feasibility of solely using in-shell nut production to forecast future production.

\section{Materials and Methods}

The characterization of national level production was derived using data from 1919 to 1990 , whereas state production was derived using data from 1940 to 1990 (generally unavailable by state before 1940). Production data were obtained from estimates reported in U.S. Dept. Agr. "Agricultural Statistics" handbooks (U.S. Dept. Agr., 1920 to 1990). U.S. in-shell pecan production is classified as either cultivar (originates from major cultivar or improved sources) or seedling (originates from wild or unimproved seedling sources and typically includes nuts from minor cultivars). Nuts wholesaled in the relatively minor pecan producing states of California, Missouri, Tennessee, Kentucky, Iowa, Kansas, Virginia, and Illinois are excluded from this study because production records are generally unavailable from these sources from 1940 to 1990. Production from Arizona is also excluded because of the absence of published production for most years [Arizona production is substantial, with the level and pattern about that of New Mexico (Wood et al., 1990); therefore, conclusions about New Mexico are likely to be, at least, roughly applicable to Arizona].

Production trends and relationships. In-shell production (in metric tons) was statistically evaluated to determine trends and associations using correlation, spline-curve, and curvilinear re-

Abbreviations: CV, cultivar; SG, seedling. 
gression techniques (SAS Institute 1987, 1988).

Production cycles and forecasting. Alternate bearing cycles were initially investigated by using the alternate bearing parameters reported by Pearce and Dobersek-Urbanc (1967) and adapted from that presented hy Hart (1942). The procedures used for the derivation of these biennial bearing parameters are as follows:

a) Bienniality: The quantity $\boldsymbol{B}$ is an evaluation for the existence of bienniality with limits of 0 and 1 .

$\boldsymbol{B}=$ proportion of occasions where the direction or trend of production changes (increased or decreases) from the preceding year.

$$
\text { Standard deviation }=\mathrm{s}_{\mathrm{n}}=(0.666)\left(\frac{100 \sqrt{16 n-2.9}}{3(n-2)}\right)
$$

$\mathrm{n}=$ number of years.

b) Intensity of bienniality: The quantities $\boldsymbol{K}$ and $\boldsymbol{E}$ measure the intensity or magnitude of the biennial effect. $K$ has limits of 0 and 1.

$$
K=\sqrt{\left(\frac{1}{n-1}\right)\left[\left(\frac{a_{2}-a_{1}}{a_{2}+a_{1}}\right)^{2}+\left(\frac{a_{3}-a_{2}}{a_{3}+a_{2}}\right)^{2}+\ldots+\left(\frac{a_{(n-1)}-a_{n}}{a_{(n-1)}+a_{n}}\right)^{2}\right]}
$$

2) $\boldsymbol{E}$ has limits of 0 to 2 with a value of one reflecting random variation. For $\boldsymbol{E}$, values approaching two reflect increasing intensity of biennial bearing, whereas values approaching 0 represent and increasing trend.

$$
E=\left(\frac{1}{2}\right)\left(\frac{\sum_{i=1}^{n}\left(x_{i}-x_{1.1}\right)^{2}}{\sum_{i=1}^{n}\left(x_{1}-x\right)}\right)
$$

Standard deviation $=s_{n-1}=\sqrt{\frac{(n-2)}{\left(n^{2}-1\right)}}$

$\mathrm{n}=$ number of years

Since $\boldsymbol{B}$ and $\boldsymbol{E}$ are sensitive to trends and, since pecan production in the United States and in individual states generally exhibit either an increasing or decreasing trend over time, the calculation of these quantities was based on detrended data using regression methods. The quantity $\boldsymbol{K}$ is relatively insensitive to trends and was calculated using actual data.

The production pattern was characterized by using a wide variety of univariate models of the following general forms: $f(y)=$ $a+b f(x), y=a+b f_{1}(x)+c f_{2}(x), y=a+b f_{1}(x)+c f_{2}(x)+d f_{3}(x)$ polynomials up to the 10 th order and rational polynomials up to the 5th order [functions include: $x^{1 / 2}, x, x^{2}, x^{3}, x^{-1}, x^{-2}, \ln x, e^{x}, e^{-x}$ Gaussian, Log-Normal, Sigmoidal, and Sine options; $x$ is equal to year (AD)] (TableCurve, 1991). Attempts to integrate the cycling nature of pecan production into a forecasting model also included stepwise autoregression (SAS-AutoReg; SAS Institute, 1988), which combined a time trend model $\left(x_{1}=b_{0}+b_{1} t+b_{2} t^{2}+e^{t}\right)$ for describing a long-term deterministic change with an autoregressive time series model $\left(x_{t}=a_{0}+a_{1} x_{t-1}+a_{2} x_{t-2}+\ldots+a_{p} x_{1-p}+e_{t}\right)$ for describing short-term fluctuations. Residuals (variation associated with the difference between the estimated trend regression and actual production data) were used to compute the autocovariances to lags from 1 to 16 years, and values were then regressed against the lags to generate the forecast model.

\section{Results and Discussion}

The following discussion of production characteristics of the U.S. pecan industry is limited to in-shell nuts marketed at the wholesale level.

General production characteristics. CV and SG production has generally been highly variable in the 11 most important pecan producing states (Figs. 1 and 2). Based on a spline-curve fitting strategy (Fig. 1), recent (since 1980) production of CV class nuts

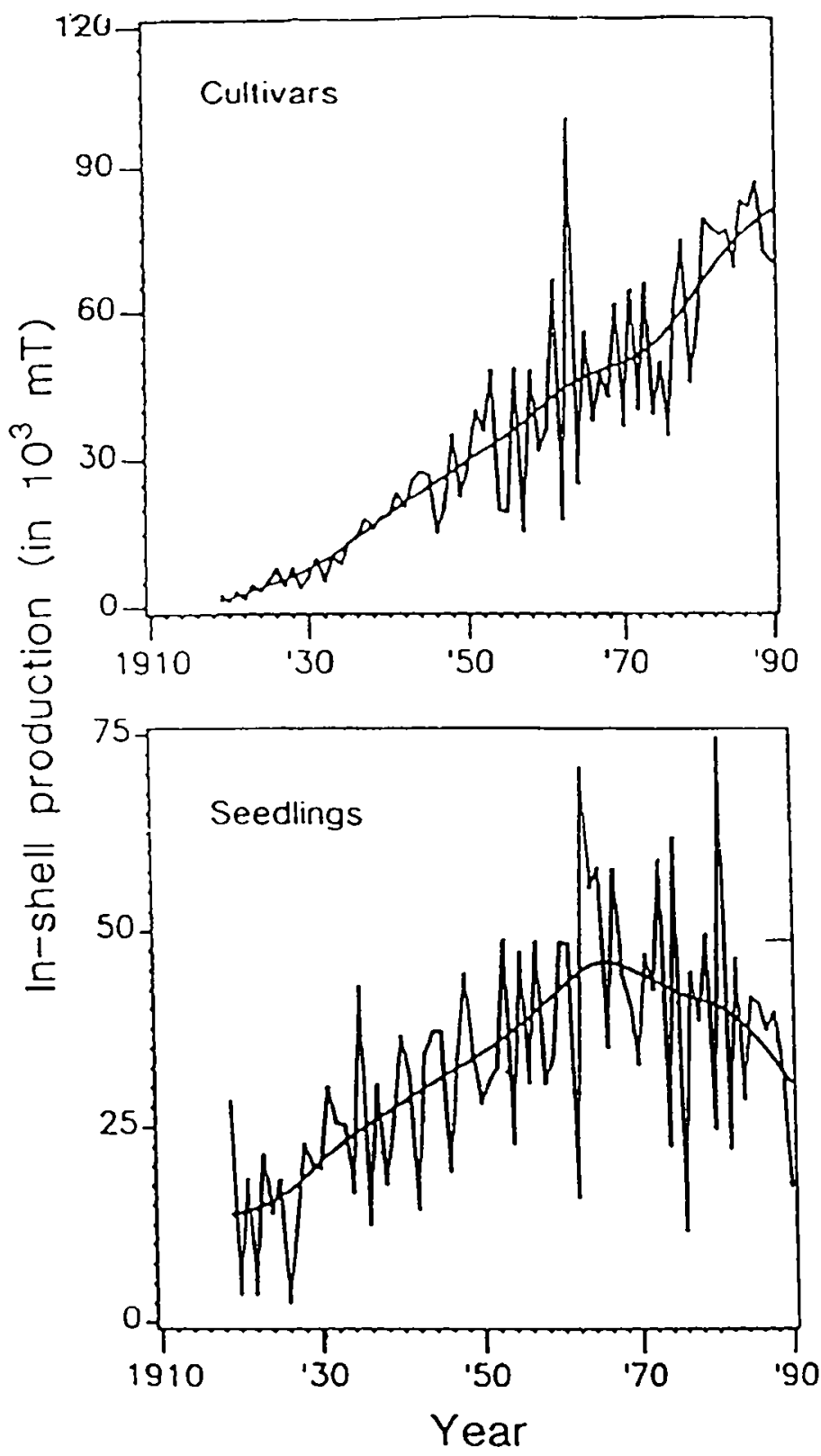

Fig. 1. National in-shell pecan production from 1919 to 1990 by cultivar (primary commercial cultivars) and seedling [comprised of noncultivar genotypes (termed natives and scedlings) and axillary cultivars] classes. 

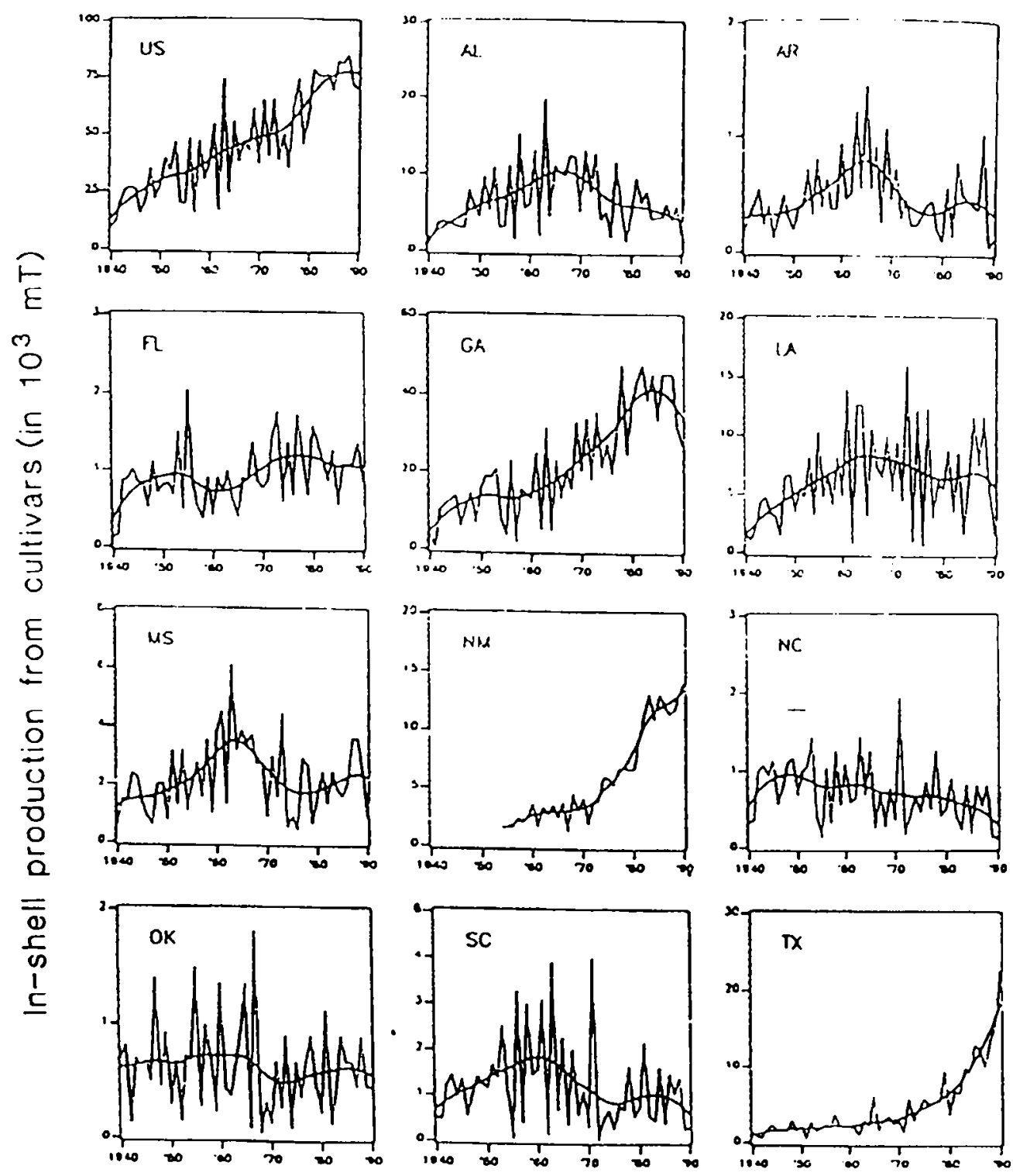

Fig. 2. Production of cultivar-class in-shell pecans by major pecan producing states since 1940.

has only increased in New Mexico and Texas. CV production from all other states either declined (Georgia, Alabama, Arkansas, North Carolina, South Carolina), remained unchanged (Louisiana, Oklahoma), or only slightly increased (Florida, Mississippi). The production of SG class nuts is currently unchanged or decreasing in Alabama, Arkansas, Georgia, North Carolina, South Carolina, and Texas (the primary producer of SG class nuts) (Fig. 2), and since 1980, in all states. The relatively recent decline in SG nuts from Texas, Louisiana, and Georgia is especially significant, since they are major producers of such nuts (Fig. 2).

Georgia has been the leading producer of CV class nuts $(46 \%$ overall) since state production records were first available (Table 1 ). This production level has been $\approx 3$-fold higher than that of the second ranking state (Alabama at $15 \%$ ). Since 1980 , the lead producers of CV-type nuts have been Georgia, Texas, and New Mexico (also Arizona), with levels increasing rapidly in Texas and New Mexico (also Arizona) (Fig. 1). Production of CV-type nuts have been declining in Georgia since about 1980; however, it is still the leading state for CV type nut production (Fig. 1). Historically, SG production has been highest from Texas $(34 \%)$. with Oklahoma (18\%), and Louisiana (15\%) ranking second and third and producing about one-half as much as Texas (Table 1). Cultivars made up 70\%' of the production from Alabama, Georgia, New Mexico, North Carolina, and South Carolina, whereas seedlings make up 70\%' of production from Louisiana, Oklahoma, Arkansas, and Texas. However, since 1980, CV production in Texas has far surpassed that of SG production (Figs. 1 and 2).

Variations in the national production of $\mathrm{CV}$ and $\mathrm{SG}$ class nuts is, therefore, most likely to be influenced by factors regulating production in Georgia and Texas, respectively (Figs. 1 and 2; Table 1 ); in fact, CV class production in Georgia is highly correlated (I = 0.96) with national CV production (Table 2). Additionally, based on the magnitude of slopes of linear regression estimates of state production (Tables 1 and 2), the percentage contribution of $\mathrm{CV}$ type production has resulted in Georgia, New Mexico (and Arizona), and Texas, exercising an increasingly dominant role, with that by Georgia being most prominent (However, the recent trend for Georgia is that of declining CV production). Similarly, the significance for the role of Georgia and Alabama in the production of SG class nuts increased from 1940 to $\approx 1980$, when production in both states began to decline. It is significant that of the 11 major pecan producing states, only Georgia, New Mexico (also Ariz.), 


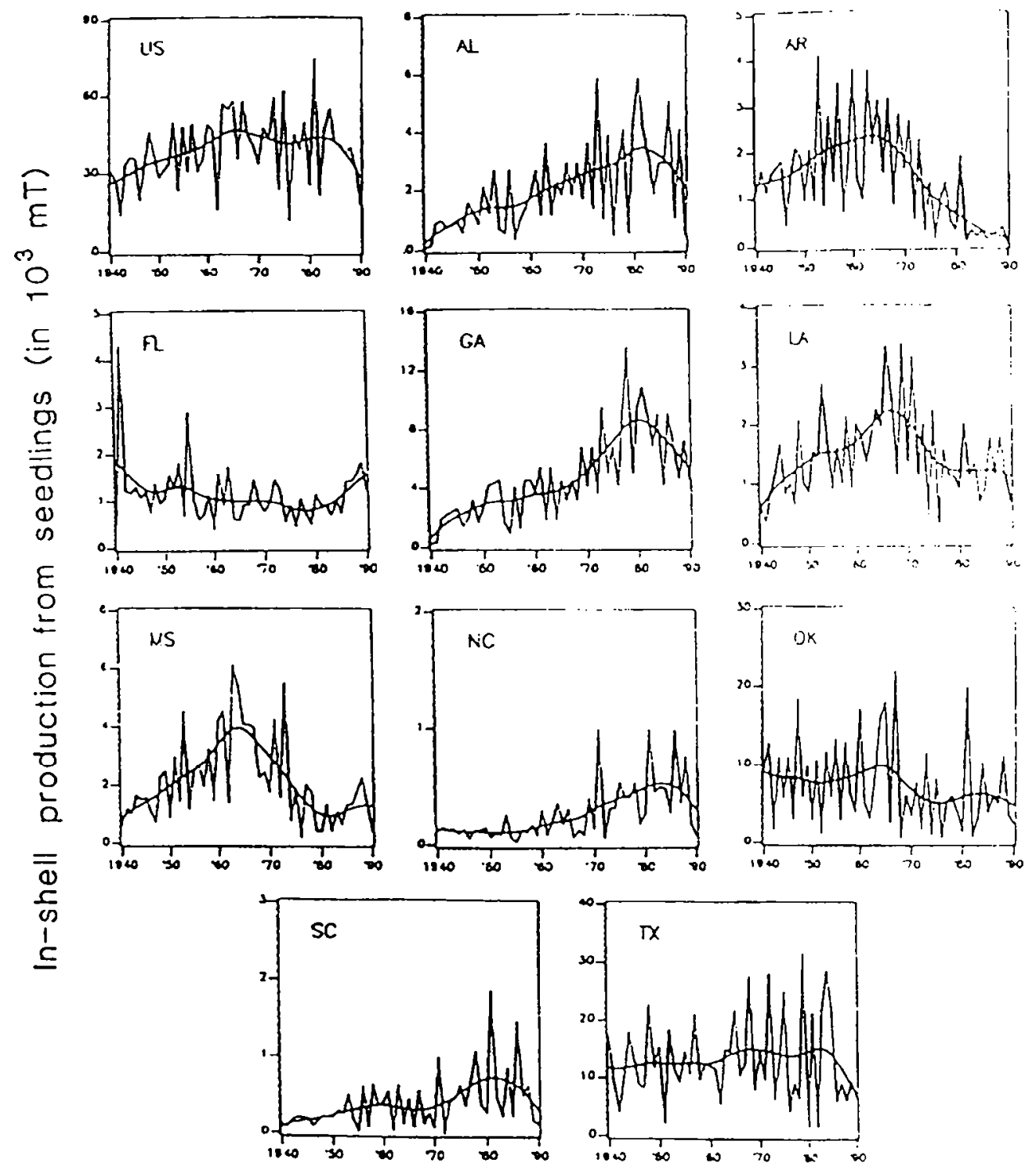

Fig. 3. Production of seedling-class in-shell pecans by major pecan producing states since 1940.

and Texas are contributing a substantial ever-increasing percentage of U.S. pecan production and are, therefore, having an increasing impact on production characteristics. This trend is advantageous for the industry as a whole, since these are climatically and geographically distinct, hence potentially buffering fluctuations in national production.

Intrastate relationships. The production of $\mathrm{CV}$ and $\mathrm{SG}$ class nuts within individual states was mutually associated (for both actual and detrended data) in all 11 producing states; however, there were relatively strong CV-SG correlations only in Georgia ( $r$ $=0.77)$, Mississippi $(r=0.89)$, and Oklahoma ( $r=0.91)$ (Table 2). The relatively weak correlations between CV and SG class production in Alabama, Arkansas, Florida, Louisiana, North Carolina, South Carolina, and Texas is evidence that trees of these two classes are either being exposed to different environmental (including economic) factors or are differentially interacting with environmental factors (including economic).

Interstate relationships. Production of $\mathrm{CV}$ or $\mathrm{SG}$ class nuts in any one state was not observed to be negatively related to production in any other state, implying that environmental factors, or other factors that might suppress yield during this period, were either relatively constant over all states or were random across states (Table 2). This characteristic was not masked by the growth in production generally exhibited by each state, because data were detrended before analysis.

There were, however, positive interrelationships among most states for CV and SG class production nuts (Table 2). CV or SG class production in Florida, New Mexico, Oklahoma, and Texas were generally unrelated, or poorly related, to that of the same class in other states; however, Texas CV production is closely associated with production from New Mexico. This association is likely due to the close proximities and age of trees of the CV-producing areas in both states. The closest relationships were between South Carolina and North Carolina, and between Alabama and Mississippi [for both, CV or SG class nuts $(r=0.91)$ ]. Production (CV or $\mathrm{SG})$ from Georgia, the primary producing state, is moderately $(r \leq$ 0.65) related to that from the surrounding states of Alabama, South Carolina, and North Carolina; however, CV class production from Georgia is highly associated with U.S. production $(r=0.96)$. For SG class nuts, production from Louisiana has been closely associated $(r=0.70)$ with U.S. SG production. Production of SG class nuts from Texas, the second leading nut producer, was only weakly 
Table 1. Primary historical sources of in-shell cultivar (CV) and seedling (SG) pecan production ( 1940 to 1991) within the United States, also slopes of linear regression of percentage contribution to U.S. production of CV and SG class pecan production since 1940 on year. ${ }^{7}$

\begin{tabular}{|c|c|c|c|c|c|c|c|}
\hline \multirow[b]{2}{*}{ Location } & \multicolumn{3}{|c|}{$\begin{array}{l}\text { Mean proportion of } \\
\text { U.S. total }(\%)\end{array}$} & \multicolumn{2}{|c|}{$\begin{array}{l}\text { Mean proportion of } \\
\text { state total }(\%)\end{array}$} & \multicolumn{2}{|c|}{$\begin{array}{l}\text { Slopes of linear } \\
\text { regression }\end{array}$} \\
\hline & $\mathrm{CV}$ & SG & $\overline{\text { Both }}$ & $\mathrm{CV}$ & SG & $\mathrm{CV}$ & SG \\
\hline$\overline{\text { Ala. }}$ & 15 & 5 & 10 & 77 & 23 & -0.002 & 0.001 \\
\hline Ark. & 1 & 4 & 2 & 30 & 70 & -0.0003 & -0.001 \\
\hline Fla. & 4 & 3 & 3 & 54 & 46 & -0.002 & NS \\
\hline $\mathrm{Ga}$. & 46 & 13 & 30 & 82 & 18 & +0.004 & +0.004 \\
\hline La. & 4 & 15 & $y$ & 23 & 77 & -0.002 & NS \\
\hline Miss. & 6 & 5 & 5 & 52 & 48 & -0.001 & -0.0006 \\
\hline N.C. & 2 & 1 & 1 & 72 & 28 & -0.0007 & +0.0002 \\
\hline N.M. & 11 & $--^{y}$ & 5 & 100 & $\ldots y$ & +0.003 & $--y^{y}$ \\
\hline Okla. & 2 & 18 & 10 & 9 & 91 & -0.0007 & -0.004 \\
\hline S.C. & 3 & 1 & 2 & 75 & 25 & -0.001 & +0.0002 \\
\hline Texas & 10 & 34 & 22 & 26 & 74 & +0.002 & is \\
\hline
\end{tabular}

'Published data are unavailable for Arizona because it originates from a small number of growers; however, its level and pattern is very similar to that of New Mexico. Due to rounding of values, sums do not necessarily equal $100 \%$. Equations are significant at the $\geq 95 \%$ level of confidence. NS means not significant at the $95 \%$ level.

yo significant seedling nut production originates from New Mexico.

associated with U.S. production; however, SG production was moderately related to U.S. production $(r=0.68)$. The generally weak between-state relationships can be interpreted as partial evidence that large scale factors, such as macroclimatic events, have perhaps had a relatively weak trend-type influence on regional production since 1940 , or that such an influence is being largely obscured by localized microenvironmental stresses (e.g., pecan weevil, aphids, hickory shuckworm, anthracnose, scab. hurricanes, drought, etc.).

National and state biennial characteristics. An analysis of national production using the parameter $\boldsymbol{B}$ indicates a biennial characteristic for both CV and SG classes (Table 3 ). The quantification of the magnitude of these biennial cycles, by three alternate bearing parameters $(\boldsymbol{K}, \boldsymbol{B}$, and $\boldsymbol{E})$, indicated that cycling was occurring at a relatively low to moderate intensity (Table 3 ). The
$\boldsymbol{K}$ parameter was relatively low for both nut classes $(<0.54)$ indicating that the year-to-year fluctuations in national yield has been low to moderate. This conclusion is supported by obtaining a value of $\approx 1.41$ for the parameter $\boldsymbol{E}$ (a value of 2.0 for $\boldsymbol{E}$ describes about the same relationship as a value of 1.0 for $K$, and a value of 1.0 is analogous to 0.0 for $\boldsymbol{K}$ ). A partitioning of the historical production record into 12 -year periods indicated that the magnitude of biennial bearing occurring for $\mathrm{CV}$ class nuts has remained relatively high from 1912 to the present (Table 3). The magnitude of the intensity parameters ( $\boldsymbol{K}$ and $\boldsymbol{E}$ ) for CV class nuts appear to have declined substantially during the last 12 years (Table 3 ). Production at the national level therefore appears to be stabilizing, presumably due to better use of cultural and pest management options. Conversely, the biennial bearing nature of SG class nuts is such that $\boldsymbol{B}$ has remained relatively static throughout the years,

Table 2. The relationship between U.S. producing states for total pecan nut production and the relationship between cultivar and seedling class nuts produced within major producing states. Correlation coefficients $(r)$ are for in-shell pecan production from 1940 to 1991."

Within nut class correlation coefficients $(r)$ for between states

Correlation between nut classes $(r)$

Location/seed-

Location/cultivar class

\begin{tabular}{|c|c|c|c|c|c|c|c|c|c|c|c|c|c|c|}
\hline \multirow{2}{*}{ ling class } & & & & & & & & & & & & & \\
\hline & Ala. & Ark. & Fla. & $\mathrm{Ga}$ & La. & Miss. & N.C. & N.M. & Okla. & S.C. & Texas & $\overline{\text { U.S. }}{ }^{y}$ & Detrended & Actual \\
\hline Ala. & & 0.45 & $--^{x}$ & 0.29 & 0.61 & 0.80 & 0.35 & -0.39 & --- & 0.64 & -- & $0 . \overline{41}$ & 0.57 & 0.53 \\
\hline Ark. & 0.35 & & -.. & --- & 0.53 & 0.53 & 0.44 & -0.33 & 0.50 & 0.45 & --- & --- & 0.68 & 0.68 \\
\hline Fla. & 0.54 & -- & & --- & 0 & -- & -- & -- & -- & -- & --- & $\ldots$ & 0.41 & 0.27 \\
\hline Ga. & 0.80 & --- & 0.51 & & -- &.-- & $-\cdot$ & 0.64 & --- & 0.55 & 0.60 & 0.96 & 0.77 & 0.92 \\
\hline La. & 0.52 & 0.34 & 0.50 & 0.33 & & 0.60 & 0.37 &.- & --- & 0.42 & --- & -.. & 0.54 & 0.60 \\
\hline Miss. & 0.30 & 0.72 & -- & -- & 0.64 & & $\ldots$ & $-\ldots$ & 0.31 & 0.60 & $\ldots$ & 0.40 & 0.89 & 0.85 \\
\hline N.C. & 0.52 & -- & $\cdots$ & 0.69 & --- & -- & & $\ldots$ & --- & 0.80 & --- & -.- & 0.63 & 0.38 \\
\hline N.M. & & & & & & & & & & -0.33 & -0.91 & 0.67 & $-y^{y}$ & -- \\
\hline Okla. & -.. & 0.59 & --- & --. & -- & 0.39 & $\cdots$ & -.. & & 0.31 & $-\cdots$ & --- & 0.91 & 0.90 \\
\hline S.C. & 0.56 & $\ldots$ & --- & 0.72 & 0.30 & -- & 0.84 &.-- & -- & & & 0.28 & 0.66 & 0.54 \\
\hline Texas & --- & --- & --- & --. & --- & -- & --- & $-\cdots$ & --- &.-- & & 0.68 & 0.36 & 0.15 \\
\hline U.S. & 0.46 & 0.53 & 0.30 & 0.29 & 0.70 & 0.57 & 0.37 &.-- & 0.61 & 0.45 & 0.54 & -- & 0.37 & 0.35 \\
\hline
\end{tabular}

${ }^{\bar{z}}$ Correlation coefficients are significant at $\geq 95 \%$ level of confidence. State data were detrended because of trends in the growth of pecan production between states. Triple dashes (---) represent correlation coefficients $<95 \%$ level of confidence. Seedling nut production is trivial in New Mexico. ${ }^{2}$ No seedling production to correlate with cultivar production. 
although, intensity ( $\boldsymbol{K}$ and $\boldsymbol{E}$ ) has been erratic with the evolution of the national pattern (Table 3).

The application of stepwise autoregressive methods that used cycles with 2 to 17 year periods and incorporated a quadratic trend model to detrend actual data confirmed the biennial symmetry implied above by the parameter $\boldsymbol{B}$. This held for CV and SG class nuts at the national level, hence confirming the biennial cycle previously identified by Gemoets et al. (1976) for SG class pecans and identifying the 2.5 year cycle they suggested for $\mathrm{CV}$ class nuts as being in actuality a true biennial cycle (Tables 4 and 5). Since cropping occurs at 1-year intervals, the suggested 2.5-year cycle would have in actuality had to have been simply a statistical value, or a 2- or a 3-year cycle. The present work provides evidence for the 2-year cycle. SG class production also exhibited a significant novemennial (9-year) cycle. The 4-year cycle for SG class and the 11- to 16-year cycle for CV class nuts reported by Gemoets et al. (1976) could not be confirmed using autoregressive techniques for production up to 1991 .

The biennial bearing intensity ( $\boldsymbol{E}$ ) for $\mathrm{CV}$ class nuts produced in Alabama, Arkansas, Florida, Georgia, Louisiana, New Mexico, and Texas was relatively low during the most recent decade, whereas $E$ has been most pronounced in Oklahoma, North Carolina, and South Carolina (Table 4). The greatest biennial bearing intensity for SG class production was from Texas and Oklahoma.

Production cycles are also evident in all producing states. For example, cycling occurred for CV class nuts in all states except North Carolina and New Mexico and for SG class nuts in all states but Florida (Tables 4 and 5). Biennial cycles appear to be present for CV class nuts in Alabama, North Carolina, Oklahoma, and South Carolina. Triennial cycles were identified in Arkansas, Georgia, and Louisiana. Cycles of longer periods (4 to 16 years) were present in Alabama, Louisiana, Mississippi, New Mexico, Oklahoma, and South Carolina. SG class nuts from Alabama, Arkansas, Louisiana, North Carolina, Oklahoma, South Carolina, and Texas were also biennially cycling: whereas a triennial cycle was only detected in Mississippi. Georgia, the most significant (in terms of production) producing state, exhibits a distinct triennial cycle for $\mathrm{CV}$ nuts and a 13-year cycle for SG nuts. Texas, the next

Table 3. Biennial bearing characteristics of in-shell pecans produced in the United States. ${ }^{7}$

\begin{tabular}{|c|c|c|c|c|c|c|c|c|}
\hline \multirow{2}{*}{$\begin{array}{l}\text { Production } \\
\text { class }\end{array}$} & \multirow{2}{*}{$\begin{array}{c}\text { Biennial } \\
\text { bearing } \\
\text { parameters }\end{array}$} & \multirow{2}{*}{$\begin{array}{l}\text { Overally } \\
1919-91 \\
\end{array}$} & \multicolumn{6}{|c|}{ Production period (yrs) } \\
\hline & & & $1919-30$ & $1931-42$ & $1943-54$ & $1955-66$ & $1967-78$ & 1979-91 \\
\hline \multirow[t]{3}{*}{ Cultivar } & B & $0.77^{\circ}$ & $0.90^{\circ}$ & $0.60^{\mathrm{vs}}$ & $0.70^{\mathrm{NS}}$ & $0.90^{*}$ & $0.90^{\circ}$ & $0.75^{\mathrm{NS}}$ \\
\hline & K & 0.26 & 0.36 & 0.16 & 0.20 & 0.45 & 0.21 & 0.07 \\
\hline & $\mathrm{E}$ & $1.38^{\circ}$ & $0.50^{\circ}$ & $1.00^{\mathrm{Ns}}$ & $1.05^{\mathrm{ns}}$ & $1.68^{\circ}$ & $1.33^{\circ}$ & $0.40^{\circ}$ \\
\hline \multirow[t]{3}{*}{ Seedling } & B & $0.74^{*}$ & $0.80^{\circ}$ & $0.60^{-s}$ & $0.50^{\mathrm{ss}}$ & $0.80^{\circ}$ & $0.80^{\circ}$ & $0.83^{\circ}$ \\
\hline & K & 0.34 & 0.54 & 0.30 & 0.19 & 0.29 & 0.35 & 0.28 \\
\hline & $\mathrm{E}$ & $1.43^{\circ}$ & $1.08^{\mathrm{Ns}}$ & $1.25^{\mathrm{Ns}}$ & $1.11^{\vee 5}$ & $1.25^{\mathrm{ss}}$ & $1.55^{\circ}$ & $1.59^{\circ}$ \\
\hline
\end{tabular}

${ }^{2} \mathrm{~A} 12$-year production period is used since shorter periods result in statistical deficiencies, and longer periods substantially reduce resolution. In the case of $E$, values of $1.0 \pm 0.26$ are not significant. Values $<0.74$ and $>1.26$ indicate a trend or intensity of cycling, respectively. The quantities $\mathrm{B}$ and $\mathrm{E}$ are calculated for detrended (to adjust for long-term growth), whereas $\mathrm{K}$ are from actual data.

${ }^{y}$ The $95 \%$ critical value of a significant biennial effect (B) for this data set is 0.71 , whereas values of $E$ are statistically different from 1.0 when values are $<0.88$ and $>1.12$; hence, values $<0.88$ indicate there was a production trend, whereas values in excess of 1.12 indicate the degree of bienniality. Values for $\mathrm{K}$ did not lend themselves to statistical separation.

Table 4. Biennial bearing intensity (E) of in-shell cultivar and seedling class nuts produced by major U.S. pecan producing states.

\begin{tabular}{|c|c|c|c|c|c|c|c|c|}
\hline \multirow[b]{2}{*}{ Location } & \multicolumn{4}{|c|}{ Cultivar } & \multicolumn{4}{|c|}{ Seedling } \\
\hline & $1940-51$ & $1952-63$ & $1964-75$ & $1976-91$ & $1940-51$ & $1952-63$ & $1964-75$ & $1976-91$ \\
\hline$\overline{\text { Ala. }}$ & 1.02 & $1.42^{n}$ & 1.16 & 1.05 & 0.84 & 1.22 & $1.69^{\circ}$ & 0.88 \\
\hline Ark. & 0.79 & 1.17 & 1.19 & 1.05 & $1.17^{\circ}$ & $1.50^{\circ}$ & $1.66^{\circ}$ & 0.80 \\
\hline Fla. & $1.22^{\circ}$ & $1.27^{\circ}$ & 0.78 & $0.60^{\circ}$ & $0.63^{\circ}$ & 1.23 & 0.95 & 1.11 \\
\hline Ga. & 0.92 & $1.35^{\circ}$ & $1.40^{\circ}$ & 0.65 & 0.76 & 1.21 & $1.43^{\circ}$ & 0.88 \\
\hline La. & 1.23 & $1.26^{\circ}$ & $1.48^{\circ}$ & 0.82 & 1.04 & $1.70^{\circ}$ & $1.70^{\circ}$ & 1.22 \\
\hline Miss. & 0.88 & 1.20 & 1.00 & $0.70^{\circ}$ & 1.19 & $1.29^{\circ}$ & 1.15 & $0.36^{\circ}$ \\
\hline N.M. ${ }^{y}$ & $\ldots$ & 1.17 & 1.22 & $0.59^{\circ}$ & & & & \\
\hline N.C. & $0.66^{\circ}$ & 1.19 & $1.44^{\circ}$ & $1.25^{\circ}$ & $0.46^{\circ}$ & 1.17 & $1.39^{\circ}$ & $1.30^{\circ}$ \\
\hline Okla. & $1.47^{*}$ & $1.36^{\circ}$ & $1.42^{\circ}$ & $1.36^{\circ}$ & $1.67^{\circ}$ & $1.46^{\circ}$ & $1.27^{\circ}$ & $1.35^{\circ}$ \\
\hline S.C. & $0.68^{*}$ & $1.52^{\circ}$ & $1.42^{\circ}$ & $1.31^{\circ}$ & $0.71^{\circ}$ & $1.57^{\circ}$ & $1.56^{\circ}$ & 1.25 \\
\hline Texas & $0.52^{\circ}$ & $0.92^{\circ}$ & 1.24 & $0.98^{\circ}$ & 0.98 & 1.24 & $1.43^{\circ}$ & $1.69^{\circ}$ \\
\hline U.S. & 0.82 & $1.43^{\circ}$ & $1.62^{\circ}$ & 0.64 & 0.98 & $1.55^{\circ}$ & $1.40^{\circ}$ & $1.35^{\circ}$ \\
\hline
\end{tabular}

2Values within the range of $1.0 \pm 0.26$ are not significant (conversely, ${ }^{*}$ indicates significance). Values $<0.74$ and $>1.26$ indicate a trend or intensity of cycling, respectively. Values for $E$ were calclated using detrended production data. E ranges from 0 to 2 with 1.0 indicating no production trend or biennial bearing. Trend effect increase as values approach 0.0 and biennial bearing intensity increases as values approach 2.0 .

y There is essentially no seedling production from New Mexico. The first period for cultivars is excluded since production was minimal during this period. 


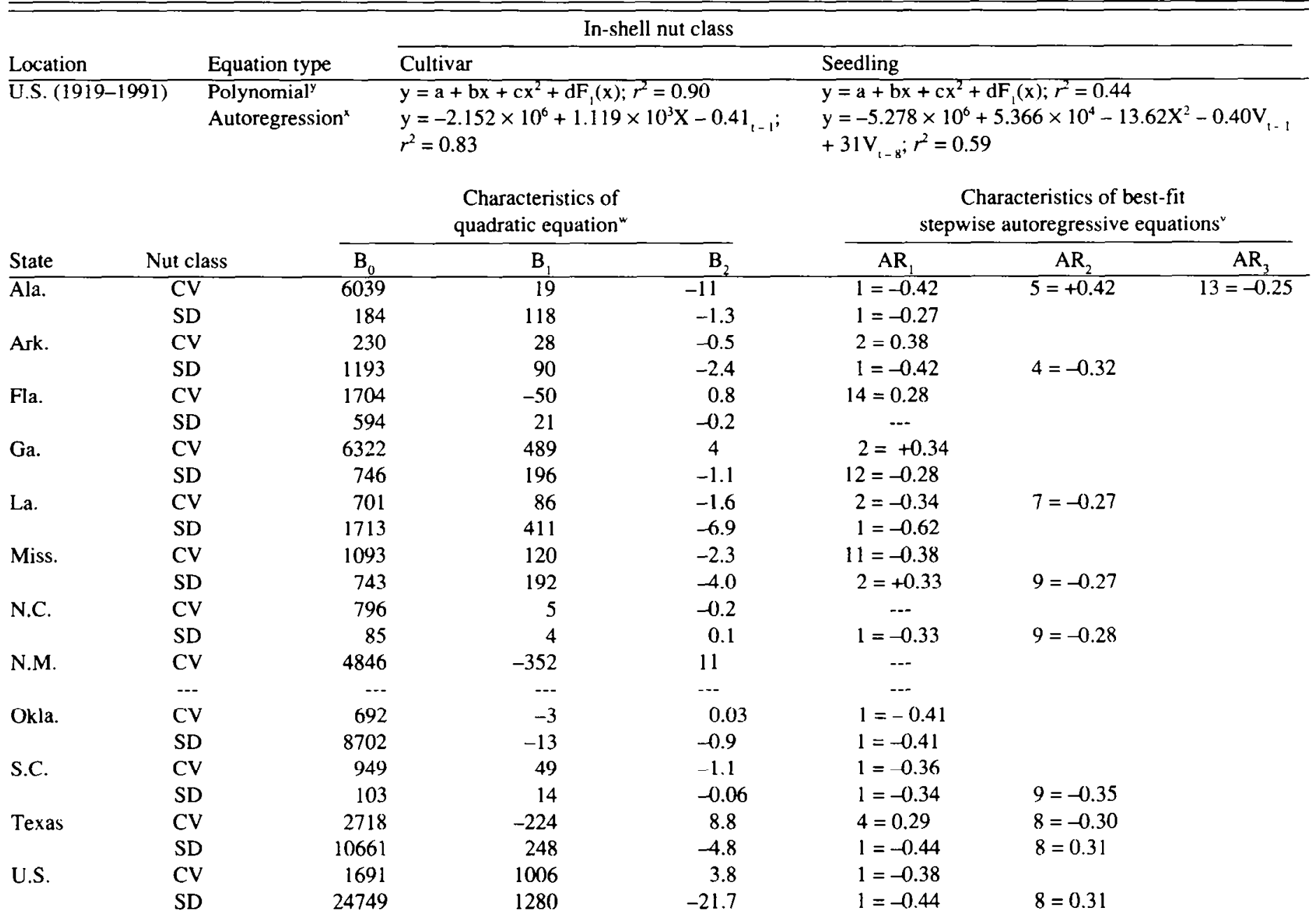

2Production (y) is in units of metric tons; equations significant at $P \leq 0.05$. Production for the United States is from 1919 to 1991 , whereas production

broken out by states is from 1940 to 1991 .
${ }^{y}$ For $C V$ class production, $y=\log$ metric tons, $a=-213358, b=236.8, c=0.0598, d=-21172.8, F_{1}=e^{\frac{(x-1981)^{2}}{2(420)^{2}}}$

For SG class production; $a=-15629, b=17.3, c=-0.0044, d=-1448, F_{1}=e^{\frac{-(x-1972)^{2}}{2(419)^{2}}}$

${ }^{x}$ The autoregressive equation for the United States production takes into account a biennial $\left(V_{t-1}\right)$ cycle for seedling-type production. $y_{1}=\beta_{0}+\beta_{1} x_{1}$ $+\beta_{2} x^{2}+v_{1}$ where $V_{1}=E_{1}-a_{1} V_{1-1}-\ldots-a p V_{1-p}$

${ }^{w} B_{0}=$ intercept, $B_{1}=$ constant for linear term, and $B_{2}=$ constant for quadratic term.

${ }^{v}$ Autogressive equation for state production patterns or cycles were tested for periods ranging from 2 to 17 years; only statistically significant ( $<<0.05$ ) periods are presented.

$\mathrm{AR}_{1}=$ Autoregressive constant for a 2 -year cycle, $\mathrm{AR}_{2}=$ autoregressive constant for a 3-year cycle, and $\mathrm{AR}_{3}=$ autoregressive constant for a 4-year cycle.

most significant state, exhibits both a 5 and 9-year cycle for $\mathrm{CV}$ nuts and a 2- and 9-year cycle for SG nuts.

Since sunspot cycles (ranging from 7 to 17 years) have been correlated with drought (Nicholson, 1989) it may be that pecan production patterns are also associated with magnetic storms on the sun via the effect of these storms on precipitation. Since precipitation data of the necessary detail are either unavailable or are very difficult to obtain, the relationship between solar activity and nut production was evaluated. A correlation of pecan production with suspot activity (from 1940 to 1973) identified a rather weak correlation coefficient of $(r=-0.50)$ for U.S. CV class nut production; hence, there was a general tendency for $\mathrm{CV}$ class production to be minimal when sun spot activity was highest. Correlations between state production and sun spots were also generally weak.
Predictability of national production. In the United States, year-to-year pecan production (both SG and CV classes) has been variable and erratic since records were first available (Figs. 1 and 2). Production of CV class nuts has tended to increase since 1919 (Fig. 1), whereas that of SG nuts increased until the mid- 1960s but has since been declining (Fig. 2). These two patterns (both CV and SG classes) are best described, within the realm of a univariate time trend regression equation, by a regression model $\left[y=a+b x+c^{2}\right.$ $\left.+\mathrm{dF}_{1}(\mathrm{x})\right]$. This model produced a coefficient of determination of 0.90 and 0.44 for the CV and SG classes, respectively (Table 5). Variability in production has, therefore, been substantially greater for SG class nuts than that of $\mathrm{CV}$ class nuts.

These models function as a less than desirable forecaster of production because there is excessive unaccounted variability; additionally, the models fail to take into account the alternate 
bearing or cyclic aspect of pecan production. Unfortunately, an attempt to better integrate periodicity into a regression or forecast model by using a univariate autoregressive model resulted in no practical improvement. For example, the best-fit time trend model (quadratic) provided coefficients of determination of 0.79 and 0.40 for CV and SC class nuts. These coefficients increased only to 0.83 and 0.59 for $\mathrm{CV}$ and SG class nuts when the autoregressive parameters (a 2-year cycle for CV nuts and a 2- and 9-year cycle for SG class nuts) were incorporated (Table 5). Hence, the autoregressive parameters, which are designed to account for cycling patterns, did not substantially add to the ability to predict production using univariate equations. When the first 66 years of production were used to forecast the last 5 years, the difference between the actual and predicted values were great enough (>10\%) to preclude the utility of the model for practical purposes. Attempts to accurately forecast production will, therefore, most likely require the adaptation of polyregressive techniques that take into account multiple factors that influence year-to-year fluctuations in production. While many variables could be used, factors such as previous year production, previous year nut quality, previous year price, nuts in cold storage, yield of associated crops, production pattern from major producing states (i.e., Georgia, Texas, and New Mexico), sunlight, rainfall cycles, hurricane activity, and sunspot activity would be likely candidates. Attempts to forecast state production using autoregressive techniques to account for cycling also generally gave poor results; hence, state levels are also likely to be sufficiently predictable using only polyregressive techniques.

Conclusions. This study provides evidence that the production patterns exhibited at the national (and probably also at the state) level are so complex that univariate models will generally not be capable of satisfactorily forecasting production at an accuracy needed by the pecan industry (Young, 1991). While a univariate polynomial regression equation coupled with a Gaussian density function can provide good fits to the data (for $\mathrm{CV}$ nuts), and are thus very good at describing past performance, they must, however, be used cautiously when used to predict future production. The presence of distinct production cycles implies that univariate prediction equations must possess a cyclic function if they are to offer utility; however, of several trigometric equations and functions evaluated in this study, none gave a sufficiently high level of predictability. Since production cycles are not absolutely biennial or triennial (etc.), an additional complex function that corrects for noise (or lapses) in cycling appears to also be necessary. Also, since pecan production is influenced by a multitude of factors (e.g., economic, marketing, biotic environmental, and abiotic environmental), a multivariate approach is probably necessary if a usable prediction equation is to be developed. Such problems might be overcome by adapting multiple regression techniques and, therefore, appear to merit the focus of future predictive efforts. While the magnitude of year-to-year changes is relatively small (less than or equal to $\approx 20 \%$ ) at the national level, it is much more severe in most states.

The biennial and triennial cycles exhibited by CV and SG class nuts in the various states are, undoubtedly, closely related to the cycling characteristic innate to individual pecan trees and are probably being entrained by local environmental stresses. The general lack of strong correlations of nut production among states implies that these entraining-stresses are not widespread and are, therefore, having little direct relationship to any climatic-scale cycles that may be operating. The greater apparent frequency of long-period cycles ( 8 to 15 years) in $\mathrm{CV}$ nuts and the general absence of such cycles in SG nuts is unexplained, but may be related to cultivation practices or simply due to chance. Additionally, sun spot activity and its subsequent impact on precipitation can not be ruled out as a significant cycle-inducing factor, although, at best, its influence is substantially moderated by other factors.

While stress factors (such as drought, spring frosts, etc.) can entrain alternate bearing cycles, there seems to be little clear evidence that such stresses are operating as such on the large-scale. This conclusion is evidenced by the between state correlations being generally weak; hence, national or regional scale entraining events appear Io be relatively rare, and production at the national level is fairly well buffered. Variability at the national level is most likely to be influenced by factors that influence production in Georgia, Texas, and New Mexico, especially since the production of nuts at the national level (CV) has been highly correlated ( $r=$ 0.96) with production in Georgia. If the current trend continues, then the production characteristic of these three states will increasingly determine the nature of the U.S. pecan industry.

\section{Literature Cited}

Epperson, J.E. and J.R. Allison. 1980. Price futures for the United States pecan industry. HortScience 15:475-478.

Fowells, H.H. 1965. Carya, p. 110-138. In: Silvics of forest trees of the United States. U.S. Dept. of Agr. Hdbk. 271.

Gemoets, E.E., L.A. Gemoets, T.E. Cannon, and R.G. McIntyre. 1976. Cycles in U.S. pecan production 1919-1974 identified by power spectral analysis. J. Amer. Soc. Hort. Sci. 101:550-553.

Hart, B.I. 1942. Significance levels for the ration of the mean square successive difference to the variance. Ann. Mathematical Stat. 13:445 447.

Monselise, S.P. and E.E. Goldschmidt. 1982. Alternate bearing in fruit trees, p. 128-173. In: Horticultural Rev., vol. 4 (J. Janick, (ed.)], AVI Publ. Co., Westport, Conn.

Nicholson, I. 1989. The sunspot cycle, p. 96. In: The sun. Rand McNally, New York.

Pearce, SC. and S. Dobersek-Urbane. 1967. The measurement of irregularity in growth and cropping. J. Hort. Sci. 42:295-305.

SAS Institute. 1988. SAS/STAT User's Guide, Release 6.03 ed. Gary, N.C.

SAS Institute, 1987. SAS/GRAPH Guide for personal computers. Version 6 ed. Cary, N.C.

Swink, J. 1991. Economics and marketing, p. 37-39. In: B. Wood and J. Payne (eds.) First national pecan workshop. Pecan husbandry: Challenges and opportunities. U.S. Dept. Agr., Agr. Res. Serv., ARS-96.

Table Curve. 1991. Jandel Scientific V.S.O. Carte Madera, Calif.

U.S. Dept. of Agriculture. 1989. Agricultural Statistics. U.S. Government Printing Office, Washington, D.C.

Wood, B.W., J.A. Payne, and L.J. Grauke. 1990. The rise of the U.S. pecan industry. HortScience 25:594, 721-723.

Wood, B.W. 1991. Alternate bearing of pecan, p. 180-190. In: B. Wood and J. Payne (eds.). First national pecan workshop. Pecan husbandry: Challenges and opportunities. U.S. Dept. Agr., Agr. Res. Serv., ARS-96.

Wright, G.C., J.B. Storey, M.K. Harris, and P.T. Sprinz. 1990. Preharvest Pecan yield estimation. HortScience 25:698-700.

Young, J.G. 1991. The future in perspective. The Pecan Press. 11(7):20-25. 